\title{
HuR Protein in Hepatocellular Carcinoma: Implications in Development, Prognosis and Treatment
}

\author{
Vasiliki Papatheofani ${ }^{1,2,+}{ }^{(0)}$, Georgia Levidou ${ }^{1,+}{ }^{+}$Panagiotis Sarantis ${ }^{1,3,+} \mathbb{D}$, Evangelos Koustas ${ }^{3}$, \\ Michalis V. Karamouzis ${ }^{3}{ }^{-}$, Alexandros Pergaris ${ }^{1}{ }^{1}$, Gregorios Kouraklis ${ }^{2}$ and Stamatios Theocharis ${ }^{1, *}$ \\ 1 First Department of Pathology, Medical School, National and Kapodistrian University of Athens, \\ 11527 Athens, Greece; vassilikipapatheofani@hotmail.com (V.P.); glevidou@yahoo.gr (G.L.); \\ psarantis@med.uoa.gr (P.S.); alexperg@yahoo.com (A.P.) \\ 2 Second Department of Propedeutic Surgery, Medical School, National and Kapodistrian University of Athens, \\ 11527 Athens, Greece; gkouraklis@med.uoa.gr \\ 3 Molecular Oncology Unit, Department of Biological Chemistry, Medical School, \\ National and Kapodistrian University of Athens, 11527 Athens, Greece; vang.koustas@gmail.com (E.K.); \\ mkaramouz@med.uoa.gr (M.V.K.) \\ * Correspondence: stamtheo@med.uoa.gr \\ + These authors contributed equally to this work.
}

Citation: Papatheofani, V.; Levidou, G.; Sarantis, P.; Koustas, E.;

Karamouzis, M.V.; Pergaris, A.;

Kouraklis, G.; Theocharis, S. HuR

Protein in Hepatocellular Carcinoma:

Implications in Development,

Prognosis and Treatment.

Biomedicines 2021, 9, 119. https://

doi.org/10.3390/biomedicines9020119

Academic Editor: Neuman Manuela

Received: 23 December 2020

Accepted: 24 January 2021

Published: 27 January 2021

Publisher's Note: MDPI stays neutral with regard to jurisdictional claims in published maps and institutional affiliations.

Copyright: (C) 2021 by the authors Licensee MDPI, Basel, Switzerland. This article is an open access article distributed under the terms and conditions of the Creative Commons Attribution (CC BY) license (https:// creativecommons.org/licenses/by/ $4.0 /)$.

\begin{abstract}
Hu-antigen $\mathrm{R}(\mathrm{HuR})$ is a post-transcriptional regulator that belongs to the embryonic lethal abnormal vision Drosophila-like family (ELAV). HuR regulates the stability, translation, subcellular localization, and degradation of several target mRNAs, which are implicated in carcinogenesis and could affect therapeutic options. HuR protein is consistently highly expressed in hepatocellular carcinoma (HCC) compared to the adjacent normal liver tissue and is involved in the post-transcriptional regulation of various genes implicated in liver malignant transformation. Additionally, HuR protein seems to be a putative prognosticator in HCC, predicting worse survival. This review summarizes the recent evidence regarding the role of HuR in primary liver tumors, as presented in clinical studies, in vitro experiments and in vivo animal models. In conclusion, our review supports the consistent role of HuR protein in the development, prognosis, and treatment of HCC. Additional studies are expected to expand current information and exploit its putative employment as a future candidate for more personalized treatment in these tumors.
\end{abstract}

Keywords: HuR; HCC; ELAV; HSC

\section{Introduction}

Hu-antigen R (HuR) or ELAV (embryonic lethal, abnormal vision Drosophila)-like protein 1 (ELAVL1) is a ubiquitously expressed RNA-binding post-transcriptional regulator, which contains three highly conserved RNA binding domains and belongs to the RNA recognition motif (RRM) superfamily [1,2]; RRM-1 and -2 bind to AU-rich elements (AREs), while RRM3, by binding to the mRNA poly(A) tail, mediates canonical RNA interactions and exists a dimerization interface localized on the $\alpha$-helical face of RRM3. Significantly, HuR binds to a U-rich sequence, usually located within the 3' untranslated region (UTR) of the target mRNAs and regulates directly or indirectly their stability, translation, and nucleo-cytoplasmic translocation $[3,4]$.

It is well-established that HuR protein translocates from the cell nucleus (abundantly expressed) to the cytoplasm along with mRNA binding [5], and this translocation is strongly associated with its regulatory function [6]. In addition, a plethora of proteins, microRNAs, hormones [7], cyclic GMP (cGMP)- elevating agents [8], and several drugs appear to alter HuR mRNA and protein levels. Moreover, the ubiquitin-mediated proteasome system's initiation leads to HuR protein degradation and to caspase-depended mechanisms during apoptotic cell death [9]. 
Several research studies suggest that alterations in HuR protein levels or its subcellular localization associate with several human diseases, such as pathological inflammation [10], atherosclerosis [11], tissue ischemia [12] and, most significantly, carcinogenesis [13,14]. Moreover, HuR appears to regulate proteins that are involved in several cancer cell functions such as cell cycle regulation, apoptotic cell death, cell signaling, stress response and inflammation [15-17].

Many clinical studies have shown that HuR protein levels correlate with a malignant phenotype and/or patients' prognosis in various cancer types (oral, esophageal, gastric, colorectal, gallbladder, renal, urothelial, pancreatic, lung, breast, cervical, and ovarian cancer). Furthermore, current data suggest the HuR molecule acts as a potential therapeutic target in various carcinomas (glioblastoma, breast cancer), including those of the liver [14,18].

According to the above considerations, the goal of this review is to present the current information regarding the role of HuR protein in hepatocellular carcinoma (HCC), as described by in vitro experiments, in vivo animal models and clinical trials. Initially, an outline of HuR protein expression in liver cell lines and tissues is presented. Afterwards, the unique gene products modulated by HuR protein, either directly (physical interaction among HuR and the target mRNA) or indirectly, are referred. Last, the clinical significance of HuR protein expression and its potential use as a therapeutic intervention against HCC is assessed.

\section{Hepatocellular Carcinoma (HCC)}

HCC is the fifth most frequent cancer worldwide and the third leading cause of cancer death, showing an increased incidence during the last decade [19]. Eight percent $(8 \%)$ of HCC cases develop in cirrhotic livers and this pre-neoplastic condition represents the most substantial predisposing factor [20]. The molecular pathogenesis of HCC is multifarious [21,22]. The most accepted established hypothesis is a gradual process through which external stimuli provoke genetic modifications in mature hepatocytes, leading to cell death and cellular proliferation/regeneration [19]. Another theory supports that cancer cells are reprogrammed and subjected to metabolic changes, in order to respond to new conditions through post-translational modification (PTM) [23].

\section{HuR Expression in Normal Liver Tissue and Related Tumor Cell Lines}

HuR protein expression has been studied in several human and mouse liver cell lines; mouse liver progenitor 29 cell line MLP29, mouse HCC cell line SAMe-D, human hepatoma cell line HepG2, human HCC cell lines Hep3B, SNU-182, SNU-398, SNU-449, and SNU-475, as well as primary mouse hepatocytes isolated from a male C57BL6 and mainly immortalized normal hepatocytes CRL4020 [24,25]. Embade et al. reported significantly higher HuR protein levels in MLP29 and SAMe-D cell lines than in primary mouse hepatocytes and high HuR expression in the human hepatoma HepG2 cell line [24]. The same applied to the mouse HCC-derived SAMe-D cell line [26] and all human HCC cell lines examined, which showed higher HuR expression levels than normal CRL4020 cells [25]. Furthermore, immunofluorescent analyses of normal versus malignant liver tissue revealed that HuR protein is down-regulated in normal human liver samples and up-regulated in HCC samples of different aetiologies [cirrhotic patients with Hepatitis $\mathrm{C}(\mathrm{HCV})$, alcoholic steatohepatitis, and non-alcoholic steatohepatitis (NASH)], and are increased proportionately to their transformation status [27]. Similar observations were reported by Zhu et al. [25]. These findings suggested that HuR protein plays a significant role during malignant hepatocyte transformation and could also represent a novel target for intervention in diverse liver pathologies [27].

\section{HuR Target Genes and Modulators in Liver Cancer}

A summary of mRNA targets of HuR protein is presented in Table 1. Recent information suggests that HuR plays a crucial role in hepatocyte proliferation, differentiation and HCC transformation through post-transcriptional regulation of key transcripts 
involved in liver function. In particular, HuR protein is associated with the $3^{\prime} \mathrm{UTR}$ of Methionine adenosyltransferase $M A T 2 A$ mRNA, which along with $M A T 1 A$, regulates S-adenosylmethionine synthesis $(S A M e)$, an essential molecule that is associated with hepatocytes' proliferation and differentiation [27]. Several studies in HCC highlighted the correlation of MAT2A expression with de-differentiation and rapid proliferation of cancer cells. MAT2A up-regulation has been associated with liver regeneration during hepatocyte de-differentiation [28,29]. HuR/methyl-HuR and AUF1 have been identified as crucial regulators of hepatic SAMe levels during liver proliferation, de-differentiation and tumor development. This correlation was revealed by studying the expression pattern of specific mRNAs (AU-rich RNA binding factor 1 or AUF1 and HuR) and its association with MAT1A and MAT2A, mRNA levels. Therefore, HuR/methyl-HuR and AUF1 appeared to control the switch between MAT1A and MAT2A expression [27].

Table 1. HuR mRNA targets in liver tissue.

\begin{tabular}{|c|c|c|c|}
\hline mRNA Target & Function of mRNA Target & Result of HuR Intervention & REF \\
\hline$M A T 2 A$ & $\begin{array}{l}\text { catalyse the synthesis of } \\
\text { S-adenosylmethionine (SAMe) }\end{array}$ & $\begin{array}{ll}- & \uparrow \text { MAT2A } \\
- & \text { promotes hepatocyte } \\
& \text { de-differentiation in liver } \\
& \text { regeneration and human HCC }\end{array}$ & [27] \\
\hline$M d m 2$ & cell cycle regulator & $\begin{array}{ll}\text { - } & \uparrow \mathrm{Mdm} 2 \\
\text { - } & \text { growth advantage of cancer } \\
\text { cells } \\
\text { - } \quad \text { HuR is also stabilized by } \\
\text { Mdm2-mediated } \\
\text { NEDDylation }\end{array}$ & [24] \\
\hline cyclin A and cyclin D1 & cell cycle regulator & $\begin{array}{l}\text { - } \quad \uparrow \text { cyclin A and D1 } \\
\text { growth advantage of cancer } \\
\text { cells }\end{array}$ & {$[24]$} \\
\hline caspase 3 & involved in apoptosis & $\begin{array}{ll}\text { - } & \downarrow \text { caspase-3 } \\
\text { - } & \text { inhibition of apoptosis }\end{array}$ & {$[24]$} \\
\hline HAUSP & along with Mdm2 modulate p53 function & $\begin{array}{ll}- & \text { p53 stabilization } \\
\text { - } & \text { regulation of apoptotic } \\
& \text { response }\end{array}$ & [26] \\
\hline Fas & involved in apoptosis & $\begin{array}{ll}- & \downarrow \text { Fas } \\
- & \text { inhibition of Fas-mediated } \\
& \text { apoptosis }\end{array}$ & [25] \\
\hline$P D G F$ and $T G F b$ & hepatic stellate cell activators & promotion of liver fibrosis & [30] \\
\hline
\end{tabular}

Furthermore, HuR protein was found to be overexpressed in primary human HCC. Additionally, a significant association between Mdm2 and HuR proteins' expression in $\mathrm{HCC}$ cases related to $\mathrm{HCV}$ infection, was noted. Moreover, high HuR protein levels in different cell lines such as SAMe-D and MLP29 were correlated with other cell cycle regulators belonging to HuR targets, such as cyclin A and cyclin D1. Furthermore, knockdown of Mdm2 in HepG2 and MLP29 cell lines led to a substantial reduction of HuR and cyclin-A protein levels. Also, $H u R$ silencing triggered the induction of caspase- 3 activation and lowered the number of cells in the S-phase of the cell cycle in several cell lines (MLP29, SAMe-D, HepG2), suggesting that $H u R$ ablation promotes apoptosis and cell cycle arrest. Consequently, a cross-talk between $\mathrm{Mdm} 2$ and $\mathrm{HuR}$ functionality was observed. Interestingly, it has also been demonstrated that HuR was stabilized by Mdm2-depended NEDDylation (NEDDylation is a post-translational modification and it is analogous to ubiquitylation) in at least three lysine amino acid residues, securing its subcellular localization in the nucleus and protection from degradation. Mdm2/NEDD8/HuR axis plays 
an important role in liver malignant transformation and tumor progression, potentially amenable for cancer therapy [24].

An interesting interaction between HuR protein and LKB1 (serine/threonine-protein kinase 11), a tumor suppressor with recently reported oncogenic functions, has been reported. LKB1 has a crucial role in hepatocyte proliferation and liver regeneration, and its activation in mice lacking the MAT1A gene is related to spontaneous development of NASH and HCC. Martinez-Lopez et al. reported that LKB1 phosphorylation regulates the cytoplasmic localization of HuR protein, which in turn, specifically binds to the 3'UTR of HAUSP, therefore stabilizing it and raising its levels [26]. HAUSP is a nuclear ubiquitinspecific protease that targets $\mathrm{p} 53$ and $\mathrm{Mdm} 2$ proteins as substrates and, in parallel with Mdm2, has a vital role in p53 functionality [31]. The cytoplasmic accumulation of HAUSP allows HAUSP-p53 interaction and leads to a more steady cytoplasmic p53 form, thus, controlling the apoptotic response through this molecule [26].

The interference of HuR protein in the apoptosis of HCC cells was also investigated in another study, which analyzed the interaction between HuR and Fas death receptor [25]. According to this study, HCC cell lines were found to express low FasL levels and were resistant to Fas-FasL stimulation, in contrast to immortalized hepatocytes, which were FasL sensitive. Moreover, it was demonstrated that HuR was interacting with the $3^{\prime}$-UTR of Fas mRNA, blocking its translation. On the contrary, HuR silencing increased the levels of Fas and sensitized HCC cells to FasL. HuR protein seemed to effectively prevent Fas-mediated apoptosis in HCC, suggesting that targeting HuR would stimulate cell apoptosis and reverse tumorigenic properties [25].

Several studies have supported the association between HuR protein levels and cirrhosis, highly increasing the risk of HCC development. Woodhoo et al. suggested that the silence of $H u R$ in a cholestatic liver injury model reduced chemoattractant and proinflammatory genes' expression. This led to a reduction of oxidative stress, macrophage infiltration, inflammation, liver damage, and consequently, liver fibrosis. Furthermore, HuR appeared to regulate the activation of hepatic stellate cells (HSC) through PDGF and $\mathrm{TGFb}$ [30]. Consequently, the association between HuR protein expression and liver fibrosis is conducted by controlling HSC activation, liver damage, and inflammation.

Other studies also suggested the association between HuR protein and cellular processes such as apoptosis and ferroptosis. Ferroptosis has been recognized as a novel cell death mechanism, characterized by reduced cell size and increased mitochondrial membrane thickness, without the classical apoptotic or necrotic morphology [32]. Increasing protein levels of HuR triggered the initiation of autophagy and autophagosome formation [33], the key mechanism for ELAVL1-depended ferroptosis. Inhibition of autophagy through siRNA against BECN1 led to ELAVL1-enhanced ferroptosis. The interaction between BECN1 mRNA and HuR is the primary molecular event, initiating autophagy, increasing autophagic ferritin degradation and consequently leading to ferroptosis. Increasing knowledge on ferroptosis and related molecular mechanisms might lead to putative therapeutic strategies for HSC and liver fibrosis [34].

It is well-known that HuR can bind and regulate the mechanisms of subsets of mRNAs such as miRNAs and lncRNAs [35]. Several studies highlighted that HuR mediated the function of MIR22HG lncRNA in HCC cells. Recent studies suggested alterations of HuR nucleus/cytoplasm ratio strongly correlated with tumorigenesis [36]. The accumulation of $\mathrm{HuR}$ protein within the cytoplasm was associated with negative clinical cancer patients outcome [34,37]. In a recent study, Zhang et al. suggested that the MIR22HG regulates HuR subcellular localization. Moreover, wild type or mutated MIR22HG up-regulation triggered the HuR translocation from the cytoplasm to the cell nucleus. Besides, HuR also appeared to control the MIR22HG stability and intervened in the function of MIR22HG in HCC. HuR regulated the stabilization of certain tumor suppressors; thus, it may constitute a noticeable target for therapeutic strategies in cancer [38]. HuR protein molecular targets in the liver are represented in Table 1 and Figure 1. 


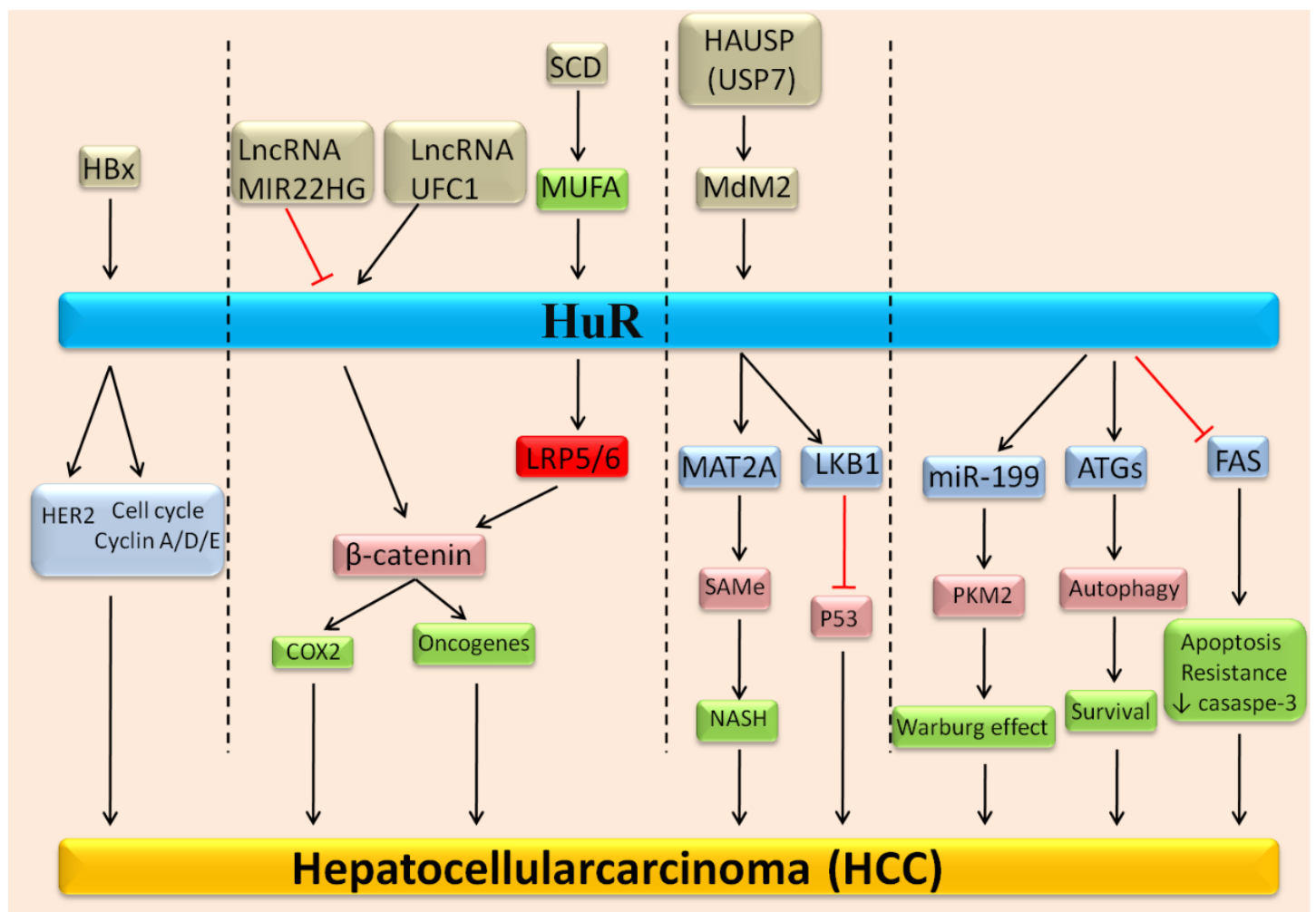

Figure 1. Molecular mechanisms that trigger the activation of $\mathrm{HuR}$ and its downstream axis that are participated in the progression of hepatocellularcarcinoma (HCC).

\section{Clinical Significance of HuR Expression}

The clinical significance of HuR expression has been studied in both HCC and other cancers. In HCC, HuR expression levels were significantly associated with advanced clinical stage and were related to low survival rates in patients with early disease stage (I or II) [25] HuR proved upregulated in breast cancer, and the elevated cytoplasmic HuR expression levels were correlated with high-grade tumors and poor patients' overall survival (OS) and disease-free survival (DFS) [39]. The elevated cytoplasmic HuR expression levels were also significantly linked to higher tumor stage in colorectal cancer. In gastric cancer, the high nuclear HuR expression levels were correlated with the depth of tumor invasion, TNM stage, and tumor size, while the cytoplasmic HuR subcellular localization was linked to poor patients' survival $[40,41]$. Cytoplasmic HuR expression was linked to histological grade, lymph node and distant metastasis in Oral Squamous Cell Carcinoma (OSCC) and lymphatic invasion in thyroid carcinoma [16]. HuR nuclear expression was also associated with reduced DFS in ovarian carcinoma patients. The opposite effect was noted in prostate carcinoma [42]. In lung adenocarcinoma, the elevated cytoplasmic HuR protein expression was linked to poor patients' clinical outcome [43].

HuR expression levels also influenced chemotherapy resistance. Pancreatic cancer patients with high HuR protein expressing tumors, treated with gemcitabine, showed a significantly longer DFS rate than those with low HuR expression [44]. On the other hand, HuR overexpression in glioma was correlated with drug resistance and increased tumor growth affecting Bcl-2 expression [45]. Additionally, HuR was found to reduce the sensitivity of liver cancer cells to radiotherapy by upregulaing the mRNA expression of mitochondrial transcription factor A (TFAM), which is linked to decreased radiosensitivity [46].

According to the above mentioned studies, it is prominent that HuR overexpression and cytoplasmic localization is related to worse cancer patients' prognosis. This is due 
to the fact that the many stress stimulators, shown to induce HuR shuttling, such as hypoxia [47] and inflammation [48], were found in precancerous and cancerous conditions. The abundantly produced HuR protein binds to mRNAs encoding proto-oncogenes, cytokines, growth factors, and invasion related factors, stabilizing them and eventually establishing a more aggressive cancer phenotype [42]. However, since HuR protein is essential for the differentiation, proliferation, metastasis and survival of HCC cancer cells, the therapeutic employment of HuR targeting might offer us the ability to regulate a wide range of HuR-mediated pro-tumorigenic effects (Figure 2).

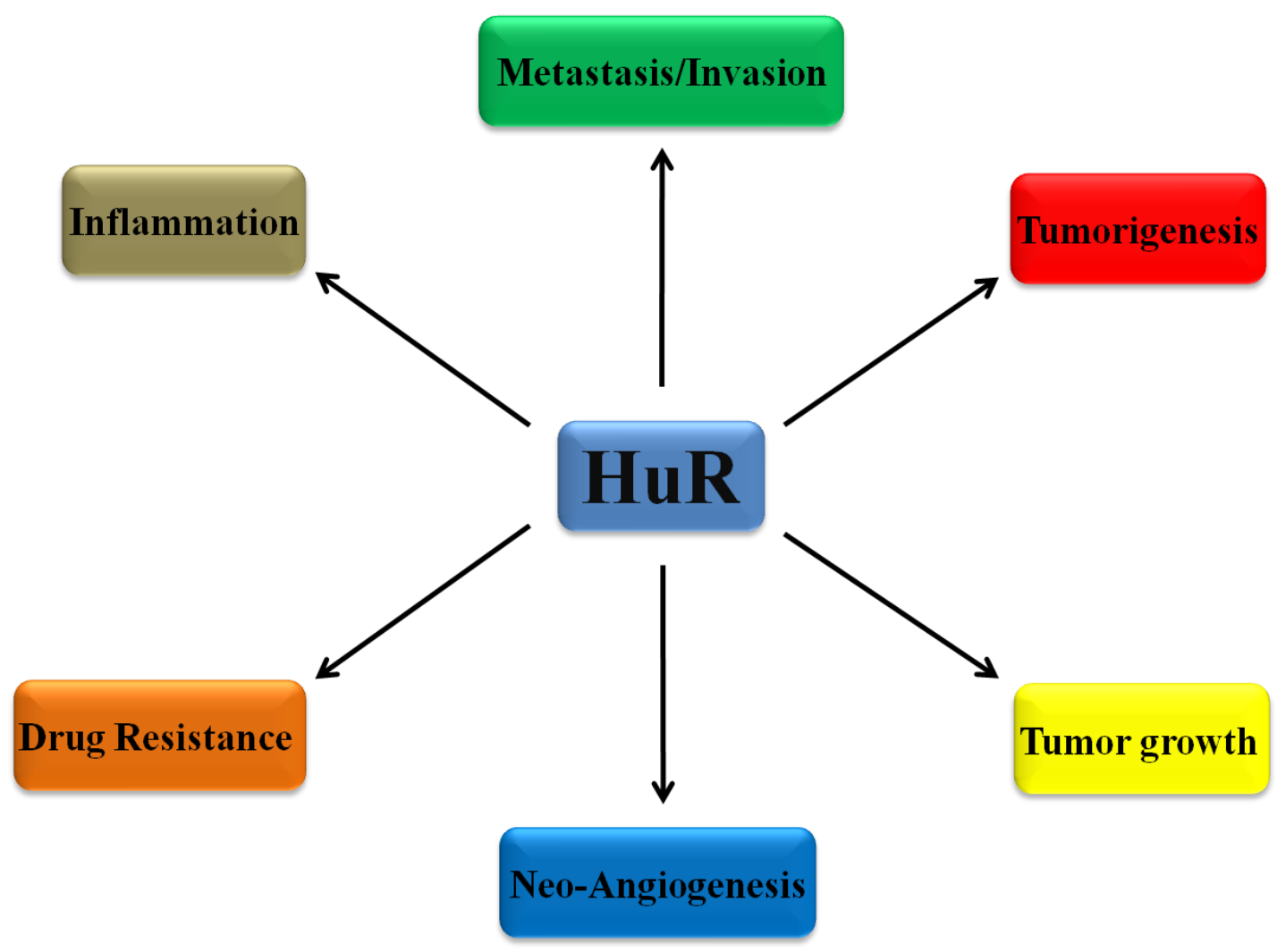

Figure 2. The diverse role of HuR in cancer development and progression through the regulation of the stability and/or translation of target mRNAs that control metastatic invasion properties of cancer cells, angiogenesis, tumor growth, inflammation and tumor resistance against multiple agents.

\section{HuR Treatment}

A recent article by Liu R et al. summarized different modes of HuR protein function targeting [49]. Targeting HuR protein with small molecules, mainly natural products, have been previously reported, although the exact mechanistic characterization of such compounds and their extensive use in experimental cellular and animal models is still lacking [38,49].

Among such molecules, the most extensively examined MS-444 [50], exerted anticancer effects by affecting HuR protein trafficking and inhibiting its homodimerization and subsequently its ability for RNA binding in different cancer types [51-54]. Another small molecule with HuR inhibitory activity, KH-3, can inhibit the growth of cancer cells, as well as their metastatic potential in in vitro and in vivo experimental models, by mediating the HuR-FOXQ1 connection [39].

Recently, CMLD-2, a small-agent that directly inhibits HuR protein, seems to display antitumor activity in non-small cell lung cancer (NSCLC) $[55,56]$ and thyroid cancer (TC) [57]. In addition, treatment of NSCLC cell lines (such as A549, HCC827, H1299, H1975) with CMLD-2 triggered G1 phase cell-cycle arrest and apoptosis in a dose-dependent pat- 
tern, when compared to its minimal effect on normal fibroblastic cells (MRC-9 and CCD-16 cell lines). CMLD-2 seemed to reduce both $H u R$ mRNA and mRNAs for other HuRdependent proteins in NSCLC cell lines. Furthermore, CMLD-2 treatment reduced the expression levels of several genes, such as cyclin $E, B c l 2, B c l-X L$ and $H u R$, while augmented those of Bax and $p 27$ in NSCLC cells $[55,58]$. CMLD-2 treatment also activated caspase-9 and -3 and induced PARP cleavage, reduced cell viability and induced apoptosis in TC cell lines (such as BCPAP, K1, $8505 \mathrm{C}$ and/or SW1736), also affecting their migration and colony formation ability. Additionally, CMLD-2 treatment reduced the HuR target protein levels, microtubules-associated protein MAD2, which is upregulated in cancer [57,59]. Similarly, it was also shown that latrunculin A, an actin-depolymerizing macrolide, and a well-known myosin II ATPase inhibitor, blebbistatin, reduced the increased the HuR protein content of HCC cell lines, Huh7 and HepG2, in a time- and dose-dependent pattern. Both inhibitors strongly decreased the abundance of cytoskeletal and membrane-bound HuR protein and conversely triggered its nuclear cell fractions in HCC [60]. In addition, both agents seemed to reduce the expression levels of COX-2, cyclin A and cyclin D1 mRNAs in HepG2 cells. The decreasing levels of cytoplasmic HuR by blebbistatin or latrunculin-A were correlated with an important sub-cellular localization of HuR mRNA cargo from polysomes to ribonucleoprotein (RNP) particles [61]. In addition, HuR-knockdown seemed to negatively affect the synthesis and migration of prostaglandin E2 in HepG2 cells. Thus, interaction with the actomyosin-dependent $\mathrm{HuR}$ sub-cellular trafficking might represent a putative therapeutic option by antagonizing the pathologic posttranscriptional gene expression by HuR protein, and consequently highlighting the beneficial effect of HuR inhibition as chemotherapeutic HCC strategy [60].

Another study investigated the inhibitory effects of N-benzylcantharidinamide, among a number of synthetic analogs of cantharidin agents, on matrix metalloproteinase (MMP)9-dependent invasive capacity of Hep3B cells. N-benzylcantharidinamide treatment suppressed, dose-dependently, Hep3B cells invasive capacity, due to HuR-mediated reduced MMP-9 mRNA stability $[62,63]$.

Several studies widely used siRNAs against $H u R$ in order to investigate its pathophysiological role [14,64]. Recently, Muralidharan et al., developed nanoparticles (NPs) in order to specifically create siRNA, targeting $H u R$. The therapeutic benefits of folate receptor(FR)- $\alpha$ (FRA)-targeted DOTAP:Cholesterol lipid nanoparticles, which carry siRNA against $H u R$ (HuR-FNP) was tested in H1299 lung cancer cell line, characterized by high levels of FRA, and in normal lung fibroblast cells (CCD16) with low or negative FRA gene expression [65].

In H1299 cells, FNP uptake was significantly higher than in CCD16 cells, implicating a receptor-dose effect. In addition, HuR-FNPs internalization process in H1299 cells was more effective through FRA-mediated endocytosis. HuR-FNP decreased HuR mRNA, further augmenting G1 phase cell-cycle arrest and triggering apoptosis in H1299 cells. No similar effect was observed when control siRNA (C-FNP) was applied [65].

Multi-functional NP-based drug delivery systems using folic acid (FA) that trigger simultaneous delivery of several therapeutic agents, such as cisplatin and siRNA for human $H u R$ mRNA, were applied in cancer cells with FR-overexpression. The dendrimerpolyethyleneimine-cis-diamminedichloroplatinum-siRNA-folic acid (Den-PEI-CDDPsiRNA-FA) NP machinery was proved beneficial in NSCLC cell lines (A549and H1299), while decreased toxicity to normal lung fibroblast cells (MRC9) [65].

It was documented that a short RNA with AU-rich elements, obtained from $\mathrm{C} / \mathrm{EBP} \beta$ 3'UTR, which bound explicitly to HuR and competed with $C / E B P \beta$ mRNA, suppressed liver cancer cell growth. Such data support the hypothesis that the suppression of cancer cell growth by 62 nt RNA, which contains the AU-rich elements, might explain the competitive binding to HuR. It was noted that a 62 nt short RNA with $3^{\prime} \mathrm{UTR}$ derived from $C / E B P$ beta mRNA, significantly competed with C/EBP beta mRNA itself for the binding of HuR, consituting the reason of $\mathrm{C} / \mathrm{EBP}$ beta inhibition and consequent suppression of HCC tumor growth [66]. According to this study, short RNA, which specifically inhibits the binding of 
HuR to its target genes (without affecting other HuR-mRNA binding interactions), might be a putative strategy for HCC and should open novel approaches for the development of anti HCC drugs. The function of the above molecules is summarized in Table 2.

Table 2. The different functions of the compounds targeting HuR.

\begin{tabular}{ccc}
\hline Compound & Function & REF \\
\hline MS-444 & Inhibits the cytoplasmic translocation & of HuR, \\
\hline N-Benzylcantharidinamide & Inhibits the cytoplasmic translocation \\
of HuR, & {$[62]$} \\
\hline Latrunculin A & Inhibits the cytoplasmic translocation \\
of HuR, & {$[60,61]$} \\
\hline Blebbistatin & Inhibits the cytoplasmic translocation \\
of HuR, & {$[60,61]$} \\
\hline HuR-FNP & $\begin{array}{c}\text { Targets HuR's mRNA and regulates } \\
\text { its expression. }\end{array}$ & {$[65]$} \\
\hline CMLD2 & Inhibits HuR binding to target mRNAs & {$[57]$} \\
\hline KH3 & Inhibits HuR binding to target mRNAs & {$[39]$} \\
\hline $\begin{array}{c}\text { Short RNA with AU-rich elements, } \\
\text { obtained from C/EBP } 3 \text { 3'UTR }\end{array}$ & $\begin{array}{l}\text { Inhibits HuR binding to target mRNAs } \\
{[66]}\end{array}$ \\
\hline
\end{tabular}

\section{Conclusions}

Increased HuR protein expression is observed in HCCs irrespective of its cause, compared to adjacent normal tissue [25,27].

Current information suggests that in $\mathrm{HCC}, \mathrm{HuR}$ protein binds to numerous mRNAs encoding proteins implicated in liver function regulation and malignant transformation. Typical examples are the post-transcriptional regulation of MAT2A mRNA, which catalyzes the principal methyl donor's synthesis and constitutes a crucial controller of hepatocyte proliferation and differentiation SAMe. Another example includes its involvement in the regulatory framework with Mdm2 and NEDD8, inducing growth advantage in HCC cancer cells.

Importantly, HuR protein appears to have clinical importance in HCCs, being correlated with advanced clinical stage. Furthermore, high HuR protein expression is linked to low survival rates of early disease-stage HCC patients [25].

Based on the previously analyzed data, the current study elucidates the significance of HuR protein in the development, prognosis, and treatment of HCC. Recent information on HuR targeting in cell lines of different origin support the notion of future use of small molecules or nanotechnology products in various cancer types, including HCC. Targeting HuR protein, affecting its molecular interactions, represents a unique opportunity to improve patients' outcome.

In conclusion, further studies are necessary in order to lay the groundwork for setting up a future, prospective and personalized patients' treatment.

Author Contributions: All authors contributed to data analysis, drafting and revising the article, gave final approval of the version to be published and agree to be accountable for all aspects of the work. V.P., G.L., P.S., E.K. and A.P., made substantial contributions to the acquisition, analysis and interpretation of data. M.V.K., G.K. and S.T. made substantial contributions in the conception, and design of the data. P.S., A.P. and S.T. made substantial contributions in drafting the manuscript and revising it critically for valuable intellectual content. The manuscript has been read and approved by all named authors and that there are no other persons who satisfied the criteria for authorship but are not listed. The order of authors listed in the manuscript has been approved by all of us. All authors have read and agreed to the published version of the manuscript.

Funding: This research received no external funding. 
Institutional Review Board Statement: Not applicable.

Informed Consent Statement: Not applicable.

Data Availability Statement: No new data were created or analyzed in this study. Data sharing is not applicable to this article.

Conflicts of Interest: The authors declare that they have no competing interests.

\section{References}

1. Ma, W.J.; Cheng, S.; Campbell, C.; Wright, A.; Furneaux, H. Cloning and characterization of HuR, a ubiquitously expressed Elav-like protein. J. Biol. Chem. 1996. [CrossRef] [PubMed]

2. Burd, C.G.; Dreyfuss, G. Conserved structures and diversity of functions of RNA-binding proteins. Science 1994. [CrossRef] [PubMed]

3. Mazan-Mamczarz, K.; Galbán, S.; De Silanes, I.L.; Martindale, J.L.; Atasoy, U.; Keene, J.D.; Gorospe, M. RNA-binding protein HuR enhances p53 translation in response to ultraviolet light irradiation. Proc. Natl. Acad. Sci. USA 2003, 100, 8354-8359. [CrossRef] [PubMed]

4. Dolicka, D.; Sobolewski, C.; de Sousa, M.C.; Gjorgjieva, M.; Foti, M. Mrna post-transcriptional regulation by au-rich elementbinding proteins in liver inflammation and cancer. Int. J. Mol. Sci. 2020, 21, 6648. [CrossRef]

5. Fan, X.C.; Steitz, J.A. HNS, a nuclear-cytoplasmic shuttling sequence in HuR. Proc. Natl. Acad. Sci. USA 1998, 95, 15293-15298. [CrossRef]

6. Keene, J.D. Why is Hu where? Shuttling of early-response-gene messenger RNA subsets. Proc. Natl. Acad. Sci. USA 1999, 96, 5-7. [CrossRef]

7. Cabilla, J.P.; Nudler, S.I.; Ronchetti, S.A.; Quinteros, F.A.; Lasaga, M.; Duvilanski, B.H. Nitric oxide-sensitive guanylyl cyclase is differentially regulated by nuclear and non-nuclear estrogen pathways in anterior pituitary gland. PLoS ONE 2011. [CrossRef]

8. Akool, E.-S.; Kleinert, H.; Hamada, F.M.A.; Abdelwahab, M.H.; Forstermann, U.; Pfeilschifter, J.; Eberhardt, W. Nitric Oxide Increases the Decay of Matrix Metalloproteinase 9 mRNA by Inhibiting the Expression of mRNA-Stabilizing Factor HuR. Mol. Cell. Biol. 2003. [CrossRef]

9. Mazroui, R.; Di Marco, S.; Clair, E.; Von Roretz, C.; Tenenbaum, S.A.; Keene, J.D.; Saleh, M.; Gallouzi, I.E. Caspase-mediated cleavage of HuR in the cytoplasm contributes to pp32/PHAP-I regulation of apoptosis. J. Cell Biol. 2008. [CrossRef]

10. Yiakouvaki, A.; Dimitriou, M.; Karakasiliotis, I.; Eftychi, C.; Theocharis, S.; Kontoyiannis, D.L. Myeloid cell expression of the RNA-binding protein HuR protects mice from pathologic inflammation and colorectal carcinogenesis. J. Clin. Investig. 2012. [CrossRef]

11. Rhee, W.J.; Ni, C.-W.; Zheng, Z.; Chang, K.; Jo, H.; Bao, G. HuR regulates the expression of stress-sensitive genes and mediates inflammatory response in human umbilical vein endothelial cells. Proc. Natl. Acad. Sci. USA 2010. [CrossRef] [PubMed]

12. Zhang, J.; Modi, Y.; Yarovinsky, T.; Yu, J.; Collinge, M.; Kyriakides, T.; Zhu, Y.; Sessa, W.C.; Pardi, R.; Bender, J.R. Macrophage $\beta 2$ integrin-mediated, HuR-dependent stabilization of angiogenic factor-encoding mRNAs in inflammatory angiogenesis. Am. J. Pathol. 2012. [CrossRef] [PubMed]

13. De Silanes, I.L.; Lal, A.; Gorospe, M. HuR: Post-Transcriptional Paths to Malignancy. RNA Biol. 2005. [CrossRef] [PubMed]

14. Kotta-Loizou, I.; Giaginis, C.; Theocharis, S. Clinical significance of HuR expression in human malignancy. Med. Oncol. 2014, 31, 1-19. [CrossRef] [PubMed]

15. Brennan, C.M.; Steitz, J.A. HuR and mRNA stability. Cell. Mol. Life Sci. 2001, 58, 266-277. [CrossRef]

16. Levidou, G.; Kotta-Loizou, I.; Tasoulas, J.; Papadopoulos, T.; Theocharis, S. Clinical significance and biological role of HuR in head and neck carcinomas. Dis. Markers 2018, 2018, 4020937. [CrossRef] [PubMed]

17. Abdelmohsen, K.; Lal, A.; Hyeon, H.K.; Gorospe, M. Posttranscriptional orchestration of an anti-apoptotic program by HuR. Cell Cycle 2007, 6, 1288-1292. [CrossRef]

18. Giaginis, C.; Sampani, A.; Kotta-Loizou, I.; Giannopoulou, I.; Danas, E.; Politi, E.; Tsourouflis, G.; Kouraklis, G.; Patsouris, E.; Keramopoulos, A.; et al. Elevated Hu-Antigen Receptor (HuR) Expression is Associated with Tumor Aggressiveness and Poor Prognosis but not with COX-2 Expression in Invasive Breast Carcinoma Patients. Pathol. Oncol. Res. 2018, 24, 631-640. [CrossRef]

19. Pons, F.; Varela, M.; Llovet, J.M. Staging systems in hepatocellular carcinoma. HPB 2005. [CrossRef]

20. Llovet, J.M.; Burroughs, A.; Bruix, J. Hepatocellular carcinoma. Lancet 2003. [CrossRef]

21. Buendia, M.-A. Genetics of hepatocellular carcinoma. Semin. Cancer Biol. 2000. [CrossRef]

22. Thorgeirsson, S.S.; Grisham, J.W. Molecular pathogenesis of human hepatocellular carcinoma. Nat. Genet. 2002, 31, 339-346. [CrossRef] [PubMed]

23. Chen, L.; Liu, S.; Tao, Y. Regulating tumor suppressor genes: Post-translational modifications. Signal Transduct. Target. Ther. 2020, 5, 90. [CrossRef]

24. Embade, N.; Fernández-Ramos, D.; Varela-Rey, M.; Beraza, N.; Sini, M.; de Juan, V.G.; Woodhoo, A.; Martínez-López, N.; Rodríguez-Iruretagoyena, B.; Bustamante, F.J.; et al. Murine double minute 2 regulates Hu antigen R stability in human liver and colon cancer through NEDDylation. Hepatology 2012. [CrossRef]

25. Zhu, H.; Berkova, Z.; Mathur, R.; Sehgal, L.; Khashab, T.; Tao, R.-H.; Ao, X.; Feng, L.; Sabichi, A.L.; Blechacz, B.; et al. HuR Suppresses Fas Expression and Correlates with Patient Outcome in Liver Cancer. Mol. Cancer Res. 2015. [CrossRef] 
26. MartíNez-LóPez, N.; Varela-Rey, M.; FernáNdez-Ramos, D.; Woodhoo, A.; VáZquez-Chantada, M.; Embade, N.; Espinosa-Hevia, L.; Bustamante, F.J.; Parada, L.A.; Rodriguez, M.S.; et al. Activation of LKB1-Akt pathway independent of phosphoinositide 3-kinase plays a critical role in the proliferation of hepatocellular carcinoma from nonalcoholic steatohepatitis. Hepatology 2010. [CrossRef] [PubMed]

27. Vázquez-Chantada, M.; Fernández-Ramos, D.; Embade, N.; Martínez-Lopez, N.; Varela-Rey, M.; Woodhoo, A.; Luka, Z.; Wagner, C.; Anglim, P.P.; Finnell, R.H.; et al. HuR/Methyl-HuR and AUF1 Regulate the MAT Expressed During Liver Proliferation, Differentiation, and Carcinogenesis. Gastroenterology 2010. [CrossRef]

28. Cai, J.; Mao, Z.; Hwang, J.J.; Lu, S.C. Differential expression of methionine adenosyltransferase genes influences the rate of growth of human hepatocellular carcinoma cells. Cancer Res. 1998, 58, 1444-1450.

29. Marras, V.; Massarelli, G.; Daino, L.; Pinna, G.; Bennati, S.; Carta, M.; Seddaiu, M.A.; Feo, F. Chemoprevention of Rat Liver Carcinogenesis by 5-Adenosyl-L-methionine: A Long-Term Study. Cancer Res. 1992, 52, 4979-4986.

30. Woodhoo, A.; Iruarrizaga-Lejarreta, M.; Beraza, N.; Garcia-Rodriguez, J.L.; Embade, N.; Fernandez-Ramos, D.; Matinez-Lopez, N.; Gutierre, V.; Arteta, B.; Caballeria, J.; et al. HuR contributes to Hepatic Stellate Cell activation and liver fibrosis. Hepatology 2012. [CrossRef]

31. Stevenson, L.F.; Sparks, A.; Allende-Vega, N.; Xirodimas, D.P.; Lane, D.P.; Saville, M.K. The deubiquitinating enzyme USP2a regulates the p53 pathway by targeting Mdm2. EMBO J. 2007. [CrossRef] [PubMed]

32. Wang, H.; An, P.; Xie, E.; Wu, Q.; Fang, X.; Gao, H.; Zhang, Z.; Li, Y.; Wang, X.; Zhang, J.; et al. Characterization of ferroptosis in murine models of hemochromatosis. Hepatology 2017. [CrossRef] [PubMed]

33. Ji, E.; Kim, C.; Kang, H.; Ahn, S.; Jung, M.; Hong, Y.; Tak, H.; Lee, S.; Kim, W.; Lee, E.K. RNA Binding Protein HuR Promotes Autophagosome Formation by Regulating Expression of Autophagy-Related Proteins 5, 12, and 16 in Human Hepatocellular Carcinoma Cells. Mol. Cell. Biol. 2019, 39. [CrossRef] [PubMed]

34. Yuan, Z.; Sanders, A.J.; Ye, L.; Jiang, W.G. HuR, a key post-transcriptional regulator, and its implication in progression of breast cancer. Histol. Histopathol. 2010, 25, 1331-1340. [PubMed]

35. Abdelmohsen, K.; Gorospe, M. Posttranscriptional regulation of cancer traits by HuR. Wiley Interdiscip. Rev. RNA 2010, 1, 214-229. [CrossRef] [PubMed]

36. Govindaraju, S.; Lee, B.S. Adaptive and maladaptive expression of the mRNA regulatory protein HuR. World J. Biol. Chem. 2013. [CrossRef]

37. Guo, J.; Lv, J.; Chang, S.; Chen, Z.; Lu, W.; Xu, C.; Liu, M.; Pang, X. Inhibiting cytoplasmic accumulation of HuR synergizes genotoxic agents in urothelial carcinoma of the bladder. Oncotarget 2016. [CrossRef]

38. Zhang, D.-Y.; Zou, X.-J.; Cao, C.-H.; Zhang, T.; Lei, L.; Qi, X.-L.; Liu, L.; Wu, D.-H. Identification and Functional Characterization of Long Non-coding RNA MIR22HG as a Tumor Suppressor for Hepatocellular Carcinoma. Theranostics 2018, 8, 3751-3765. [CrossRef]

39. Wu, X.; Gardashova, G.; Lan, L.; Han, S.; Zhong, C.; Marquez, R.T.; Wei, L.; Wood, S.; Roy, S.; Gowthaman, R.; et al. Targeting the interaction between RNA-binding protein HuR and FOXQ1 suppresses breast cancer invasion and metastasis. Commun. Biol. 2020, 3, 1-16. [CrossRef]

40. Denkert, C.; Koch, I.; Von Keyserlingk, N.; Noske, A.; Niesporek, S.; Dietel, M.; Weichert, W. Expression of the ELAV-like protein HuR in human colon cancer: Association with tumor stage and cyclooxygenase-2. Mod. Pathol. 2006, 19, 1261-1269. [CrossRef]

41. Song, X.; Shi, X.; Li, W.; Zhang, F.; Cai, Z. The RNA-Binding Protein HuR in Digestive System Tumors. Biomed Res. Int. 2020, 2020, 9656051. [CrossRef] [PubMed]

42. Wang, J.; Guo, Y.; Chu, H.; Guan, Y.; Bi, J.; Wang, B. Multiple functions of the RNA-binding protein HuR in cancer progression, treatment responses and prognosis. Int. J. Mol. Sci. 2013, 14, 10015-10041. [CrossRef]

43. Lauriola, L.; Granone, P.; Ramella, S.; Lanza, P.; Ranelletti, F.O. Expression of the RNA-binding protein HuR and its clinical significance in human stage I and II lung adenocarcinoma. Histol. Histopathol. 2012, 27, 617-626. [CrossRef] [PubMed]

44. Oba, A.; Ban, D.; Kirimura, S.; Akahoshi, K.; Mitsunori, Y.; Matsumura, S.; Ochiai, T.; Kudo, A.; Tanaka, S.; Minoru, T. Clinical application of the biomarkers for the selection of adjuvant chemotherapy in pancreatic ductal adenocarcinoma. J. Hepatobiliary Pancreat. Sci. 2016, 23, 480-488. [CrossRef] [PubMed]

45. Filippova, N.; Yang, X.; Wang, Y.; Gillespie, G.Y.; Langford, C.; King, P.H.; Wheeler, C.; Nabors, L.B. The RNA-binding protein HuR promotes glioma growth and treatment resistance. Mol. Cancer Res. 2011, 9, 648-659. [CrossRef] [PubMed]

46. Zhang, R.; Wang, J. HuR stabilizes TFAM mRNA in an ATM/p38-dependent manner in ionizing irradiated cancer cells. Cancer Sci. 2018, 109, 2446-2457. [CrossRef] [PubMed]

47. Levy, N.S.; Chung, S.; Furneaux, H.; Levy, A.P. Hypoxic stabilization of vascular endothelial growth factor mRNA by the RNA-binding protein HuR. J. Biol. Chem. 1998, 273, 6417-6423. [CrossRef] [PubMed]

48. Suswam, E.A.; Nabors, L.B.; Huang, Y.; Yang, X.; King, P.H. IL-1 $\beta$ induces stabilization of IL-8 mRNA in malignant breast cancer cells via the $3^{\prime}$ untranslated region: Involvement of divergent RNA-binding factors HuR, KSRP and TIAR. Int. J. Cancer 2005, 113, 911-919. [CrossRef] [PubMed]

49. Liu, R.; Wu, K.; Li, Y.; Sun, R.; Li, X. Human antigen R: A potential therapeutic target for liver diseases. Pharmacol. Res. 2020, 155, 104684. [CrossRef] [PubMed]

50. Wang, Z.; Bhattacharya, A.; Ivanov, D.N. Identification of Small-Molecule Inhibitors of the HuR/RNA Interaction using a fluorescence polarization screening assay followed by NMR validation. PLoS ONE 2015, 10. [CrossRef] [PubMed] 
51. Aotani, Y.; Saitoh, Y. Structure Determination of MS-444; a New Myosin Light Chain Kinase Inhibitor. J. Antibiot. 1995, 48, 952-953. [CrossRef] [PubMed]

52. Meisner, N.C.; Hintersteiner, M.; Mueller, K.; Bauer, R.; Seifert, J.M.; Naegeli, H.U.; Ottl, J.; Oberer, L.; Guenat, C.; Moss, S.; et al. Identification and mechanistic characterization of low-molecular-weight inhibitors for HuR. Nat. Chem. Biol. 2007, 3, 508-515. [CrossRef]

53. Blanco, F.F.; Preet, R.; Aguado, A.; Vishwakarma, V.; Stevens, L.E.; Vyas, A.; Padhye, S.; Xu, L.; Weir, S.J.; Anant, S.; et al. Impact of HuR inhibition by the small molecule MS-444 on colorectal cancer cell tumorigenesis. Oncotarget 2016, 7, 74043-74058. [CrossRef] [PubMed]

54. Lang, M.; Berry, D.; Passecker, K.; Mesteri, I.; Bhuju, S.; Ebner, F.; Sedlyarov, V.; Evstatiev, R.; Dammann, K.; Loy, A.; et al. HuR small-molecule inhibitor elicits differential effects in adenomatosis polyposis and colorectal carcinogenesis. Cancer Res. 2017, 77, 2424-2438. [CrossRef] [PubMed]

55. Muralidharan, R.; Mehta, M.; Ahmed, R.; Roy, S.; Xu, L.; Aubé, J.; Chen, A.; Zhao, Y.D.; Herman, T.; Ramesh, R.; et al. HuR-targeted small molecule inhibitor exhibits cytotoxicity towards human lung cancer cells. Sci. Rep. 2017, 7. [CrossRef] [PubMed]

56. Muralidharan, R.; Babu, A.; Amreddy, N.; Srivastava, A.; Chen, A.; Zhao, Y.D.; Kompella, U.B.; Munshi, A.; Ramesh, R. Tumortargeted nanoparticle delivery of HuR siRNA inhibits lung tumor growth in vitro and in vivo by disrupting the oncogenic activity of the RNA-binding protein HuR. Mol. Cancer Ther. 2017, 16, 1470-1486. [CrossRef]

57. Allegri, L.; Baldan, F.; Roy, S.; Aubé, J.; Russo, D.; Filetti, S.; Damante, G. The HuR CMLD-2 inhibitor exhibits antitumor effects via MAD2 downregulation in thyroid cancer cells. Sci. Rep. 2019, 9. [CrossRef] [PubMed]

58. Giaginis, C.; Alexandrou, P.; Tsoukalas, N.; Sfiniadakis, I.; Kavantzas, N.; Agapitos, E.; Patsouris, E.; Theocharis, S. Huantigen receptor (HuR) and cyclooxygenase-2 (COX-2) expression in human non-small-cell lung carcinoma: Associations with clinicopathological parameters, tumor proliferative capacity and patients' survival. Tumor Biol. 2014, 36, 315-327. [CrossRef]

59. Giaginis, C.; Alexandrou, P.; Delladetsima, I.; Karavokyros, I.; Danas, E.; Giagini, A.; Patsouris, E.; Theocharis, S. Clinical Significance of Hu-Antigen Receptor (HuR) and Cyclooxygenase-2 (COX-2) Expression in Human Malignant and Benign Thyroid Lesions. Pathol. Oncol. Res. 2016, 22, 189-196. [CrossRef]

60. Doller, A.; Badawi, A.; Schmid, T.; Brauß, T.; Pleli, T.; Zu Heringdorf, D.M.; Piiper, A.; Pfeilschifter, J.; Eberhardt, W. The cytoskeletal inhibitors latrunculin A and blebbistatin exert antitumorigenic properties in human hepatocellular carcinoma cells by interfering with intracellular HuR trafficking. Exp. Cell Res. 2015, 330, 66-80. [CrossRef]

61. Eberhardt, W.; Badawi, A.; Biyanee, A.; Pfeilschifter, J. Cytoskeleton-dependent transport as a potential target for interfering with post-transcriptional HuR mRNA regulons. Front. Pharmacol. 2016, 7, 251. [CrossRef] [PubMed]

62. Lee, J.-Y.; Chung, T.-W.; Choi, H.-J.; Lee, C.H.; Eun, J.S.; Han, Y.T.; Choi, J.-Y.; Kim, S.-Y.; Han, C.-W.; Jeong, H.-S.; et al. A novel cantharidin analog N-ABenzylcantharidinamide reduces the expression of MMP-9 and invasive potentials of Hep3B via inhibiting cytosolic translocation of HuR. Biochem. Biophys. Res. Commun. 2014, 447, 371-377. [CrossRef] [PubMed]

63. Mittelstadt, M.L.; Patel, R.C. AP-1 mediated transcriptional repression of matrix metalloproteinase- 9 by recruitment of histone deacetylase 1 in response to interferon $\beta$. PLoS ONE 2012, 7. [CrossRef] [PubMed]

64. Ahmed, R.; Amreddy, N.; Babu, A.; Munshi, A.; Ramesh, R. Combinatorial nanoparticle delivery of siRNA and antineoplastics for lung cancer treatment. In Methods in Molecular Medicine; Humana Press Inc.: Clifton, NJ, USA, 2019; Volume 1974, pp. 265-290.

65. Muralidharan, R.; Babu, A.; Amreddy, N.; Basalingappa, K.; Mehta, M.; Chen, A.; Zhao, Y.D.; Kompella, U.B.; Munshi, A.; Ramesh, R. Folate receptor-targeted nanoparticle delivery of HuR-RNAi suppresses lung cancer cell proliferation and migration. J. Nanobiotechnol. 2016, 14, 47. [CrossRef] [PubMed]

66. Sun, D.Q.; Wang, Y.; Liu, D.G. Cancer cell growth suppression by a 62nt AU-rich RNA from C/EBP $\beta$ 3'UTR through competitive binding with HuR. Biochem. Biophys. Res. Commun. 2012, 426, 122-128. [CrossRef] [PubMed] 